\title{
Anti-CDC25B autoantibody predicts poor prognosis in patients with advanced esophageal squamous cell carcinoma
}

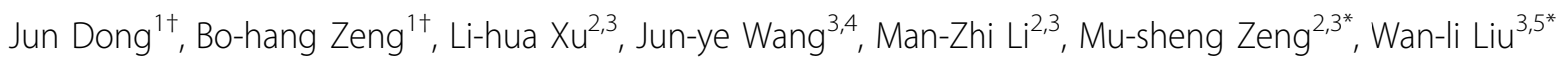

\begin{abstract}
Background: The oncogene CDC25B phosphatase plays an important role in cancer cell growth. We have recently reported that patients with esophageal squamous cell carcinoma (ESCC) have significantly higher serum levels of CDC25B autoantibodies (CDC25B-Abs) than both healthy individuals and patients with other types of cancer; however, the potential diagnostic or prognostic significance of CDC25B-Abs is not clear. The aim of this study is to evaluate the clinical significance of serum CDC25B-Abs in patients with ESCC.

Methods: CDC25B autoantibodies were measured in sera from both 134 patients with primary ESCC and 134 healthy controls using a reverse capture enzyme-linked immunosorbent assay (ELISA) in which anti-CDC25B antibodies bound CDC25B antigen purified from Eca-109 ESCC tumor cells. The clinicopathologic significance of CDC25B serum autoantibodies was compared to that of the tumor markers carcinoembryonic antigen (CEA), squamous cell carcinoma antigen (SCC-Ag) and cytokeratin 19 fragment antigen 21-1(CYFRA21-1).
\end{abstract}

Results: Higher levels of CDC25B autoantibodies were present in sera from patients with ESCC $\left(A_{450}=0.917, S D=\right.$ $0.473)$ than in sera from healthy control subjects $\left(A_{450}=0.378, S D=0.262, P<0.001\right)$. The area under the receiver operating characteristic (ROC) curve for CDC25B-Abs was 0.870 (95\% Cl: $0.835-0.920$ ). The sensitivity and specificity of CDC25B-Abs for detection of ESCC were $56.7 \%$ and $91.0 \%$, respectively, when CDC25-Abs-positive samples were defined as those with an $A_{450}$ greater than the cut-off value of 0.725 . Relatively few patients tested positive for the tumor markers CEA, SCC-Ag and CYFRA21-1 (13.4\%, 17.2\%, and 32.1\%, respectively). A significantly higher number of patients with ESCC tested positive for a combination of CEA, SCC, CYFRA21-1 and CDC25B-Abs (64.2\%) than for a combination of CEA, SCC-Ag and CYFRA21-1 $(41.0 \%, P<0.001)$. The concentration of CDC25B autoantibodies in serum was significantly correlated with tumor stage $(P<0.001)$. Although examination of the total patient pool showed no obvious relationship between CDC25B autoantibodies and overall survival, in the subgroup of patients with stage III-IV tumors, the cumulative five-year survival rate of CDC25B-seropositive patients was $6.7 \%$, while that of CDC25B-seronegative patients was $43.4 \%$ ( $P=0.001$, log-rank). In the N1 subgroup, the cumulative five-year survival rate of CDC25B-seropositive patients was $13.6 \%$, while that of CDC25B-seronegative patients was $54.5 \%$ $(P=0.040$, log-rank).

Conclusions: Detection of serum CDC25B-Abs is superior to detection of the tumor markers CEA, SCC-Ag and CYFRA21-1 for diagnosis of ESCC, and CDC25B-Abs are a potential prognostic serological marker for advanced ESCC.

\footnotetext{
* Correspondence: zengmsh@mail.sysu.edu.cn; liuwl@sysucc.org.cn

+ Contributed equally

${ }^{2}$ Department of Experimental Research, Sun Yat-sen University Cancer

Center, Guangzhou, China

${ }^{3}$ State Key Laboratory of Oncology in South China and Department of

Thoracic, Sun Yat-sen University Cancer Center, Guangzhou, China

Full list of author information is available at the end of the article
}

(C) 2010 Dong et al; licensee BioMed Central Ltd. This is an Open Access article distributed under the terms of the Creative Commons 


\section{Background}

Esophageal squamous cell carcinoma (ESCC), the major histopathological form of esophageal cancer, is one of the most lethal malignancies of the digestive tract and is the fourth most frequent cause of cancer deaths in China [1]. Despite the improvements in surgical techniques and adjuvant chemoradiation for patients with ESCC, the five-year survival rate of patients with advanced ESCC is still poor [2]. This poor survival rate is largely due to the lack of serological markers for early diagnosis and prediction of disease progression; patients are frequently diagnosed with ESCC when they have already reached an advanced stage of disease [3]. There is thus a growing need to identify useful biological markers for early, non-invasive diagnosis of ESCC and for monitoring tumor progression [4].

In addition to the traditional tumor markers CEA, SCCA and CYFRA21-1, autoantibodies against tumorassociated antigens were recently reported in sera from patients with ESCC. Similar to the traditional tumor markers, these autoantibodies were shown to be useful molecular markers for ESCC. Some patients with ESCC mount an immunological reaction against several tumor-associated antigens, including p53 [5-7], myomegalin [8] and TRIM21 [9]. Recently, a proteomics-based approach identified several autoantibodies in sera of patients with ESCC, such as anti-heat shock protein 70 [10] and anti-peroxiredoxin VI [11]. The presence of these autoantibodies in sera has been reported as a useful marker for early diagnosis or for prediction of disease progression in patients with ESCC.

Most recently, we identified CDC25B autoantibodies in sera from patients with ESCC using a proteomicsbased technique[12]. Three CDC25B phosphatases exist in higher eukaryotes, CDC25A, CDC25B and CDC25C [13]. CDC25B has been shown to play an important role in tumorigenesis [14]. First, CDC25B can transform fibroblast cells lacking functional retinoblastoma protein or harboring mutated Ras protein[15]. Second, CDC25B activates the mitotic kinase CDK1/cyclin B complex in the cytoplasm to stimulate cell cycle progression [16]. Furthermore, overexpression of CDC25B has been observed in a variety of human cancers, including colon cancer[17], medullary thyroid carcinoma [18], breast cancer [19], non-Hodgkin's lymphomas[20], non-small cell lung cancer [21] and ESCC[22-25]. We previously reported that aberrant expression of CDC25B in ESCC tumor cells can induce CDC25B autoantibodies in sera of ESCC patients, and antibodies against CDC25B were detected in sera of $36.3 \%$ of patients with ESCC, but not in sera of healthy controls, by reverse capture ELISA [12]. Our findings suggest that CDC25B autoantibodies are a novel serum marker for ESCC.
Although higher levels of anti-CDC25B antibodies were found in the sera of patients with ESCC than in the sera of healthy controls, the relationship between tumor burden, tumor staging and antibody levels remains unknown. In addition, the potential utility of anti-CDC25B antibodies for diagnosis of ESCC has not been clearly addressed. In this study, we established a reverse capture ELISA to detect anti-CDC25B antibodies in sera from patients with ESCC and evaluated the clinical values of CDC25B autoantibodies for diagnosis of ESCC and prediction of tumor progression.

\section{Methods}

\section{Patients and sera}

Sera were collected from 134 patients with primary ESCC at the time of diagnosis before tumor resection at the Cancer Center of Sun Yat-sen University between January 2003 and December 2004. Ninety-three patients were male and 41 patients were female. The patients ranged in age from 38 to 81 years (mean, 58.5 years), and none of them had received radiation therapy or chemotherapy before surgery. Sera from 134 healthy volunteers (91 males and 43 females with ages ranging from 40 to 70 years (mean, 61 years)) were collected and used as controls. Prior to the use of these sera, informed consent was obtained from patients and experiments were approved by the Institute Research Ethics Committee. After collection, sera were immediately aliquoted and stored at $-80^{\circ} \mathrm{C}$ until use.

\section{Cell lines}

The ESCC cell lines Eca-109, TE-1, and Kyse140 (Cell Bank of Type Culture Collection of Chinese Academy of Sciences, Shanghai, China) were grown in RPMI 1640 (Invitrogen, Carlsbad, CA) supplemented with 10\% fetal bovine serum, $100 \mu \mathrm{g} / \mathrm{L}$ streptomycin, and $100 \mu \mathrm{g} / \mathrm{L}$ penicillin in a humidified incubator containing $5 \% \mathrm{CO}_{2}$ at $37^{\circ} \mathrm{C}$. The immortalized esophageal cell line NE-3 was obtained from Dr. Jin (the University of Hong Kong, P. R. China)[26] and cultured in KeratinocyteSFM (Invitrogen, Carlsbad, CA).

\section{Western blot analysis}

Western blots were performed as described previously [27]. The membranes were stained with a 1:1000 dilution of an anti-CDC25B antibody (Cell Signaling Technology, Danvers, MA) or with a 1:2000 dilution of a mouse monoclonal anti- $\alpha$-tubulin antibody (Santa Cruz Biotechnology, Santa Cruz, CA). A non-tumorous tissue protein was obtained from a patient with ESCC who underwent surgical esophageal tissue resection at the Cancer Center of Sun Yat-sen University (Guangzhou, P. R. China) during 2009 and used as a negative control. 


\section{Preparation of Antigen Protein}

Antigen protein was extracted from the ESCC cell lines and prepared as reported previously [28]. Briefly, after washing the cells three times with phosphate-buffered saline (PBS), the cells were collected and incubated at a concentration of $10^{7}$ cells $/ \mathrm{ml}$ in a lysis buffer composed of Tris base $(10 \mathrm{mmol} / \mathrm{L}), \mathrm{NaCl}(150 \mathrm{mmol} / \mathrm{L})$, Triton-X $(0.1 \%)$ and a proteinase inhibitor cocktail, placed on ice, vortexed every $10 \mathrm{~min}$ for $1 \mathrm{~h}$, and centrifuged at 10,000 $\times \mathrm{g}$ for $20 \mathrm{~min}$ at $4^{\circ} \mathrm{C}$. The supernatant was then collected as an antigen protein sample and stored at $-80^{\circ} \mathrm{C}$ until use. The final protein concentration was determined using a BCA protein assay kit (Thermo Fisher Scientific, Fremont, CA).

\section{Reverse capture ELISA for Detection of CDC25B Autoantibodies}

A 96-well plate (Costar) was coated overnight with purified anti-CDC25B monoclonal antibody (100 ng/well in $50 \mathrm{mM}$ bicarbonate buffer (pH 9.0), Cell Signaling Technology, Danvers, MA) at $4^{\circ} \mathrm{C}$. Wells were then blocked for $2 \mathrm{~h}$ at $37^{\circ} \mathrm{C}$ with $3 \%$ bovine serum albumin (BSA) in PBS. The antigen protein sample was diluted in PBS $(\mathrm{pH}$ 7.0) to final concentrations of $20 \mathrm{mg} / \mathrm{ml}, 10 \mathrm{mg} / \mathrm{ml}$ and $5 \mathrm{mg} / \mathrm{ml}$, added to blocked wells $(100 \mu \mathrm{l} /$ well $)$ and incubated overnight at $4^{\circ} \mathrm{C}$. Wells were then washed three times with PBST $(0.1 \%(\mathrm{v} / \mathrm{v})$ Tween 20 in PBS), and the $100 \mu \mathrm{l}$ serum samples (1:200 dilution with PBST) were incubated in the wells for $2 \mathrm{~h}$ at $37^{\circ} \mathrm{C}$. Rabbit anti-human CDC25B polyclonal antibody (1:10,000 dilution in PBST, Abcam) was used as a positive control, and 3\% BSA served as a negative control. After washing the wells four times with PBST, each well was incubated with a 1:10,000 dilution of $100 \mu$ l goat anti-human or anti-rabbit IgG-HRP conjugate (Santa Cruz Biotechnology, Santa Cruz, CA) for $1 \mathrm{~h}$ at $37^{\circ} \mathrm{C}$. The wells were then washed with PBST and incubated with TMB developing reagent for $5 \mathrm{~min}$ in the dark. The reactions were stopped with $0.5 \mathrm{~mol} / \mathrm{L} \mathrm{H}_{2} \mathrm{SO}_{4}$ and the absorbance of each well was measured at $450 \mathrm{~nm}$ using a Multiskan Spectrum plate reader (Thermo LabSystems). Sera from ESCC patients and healthy volunteers were tested simultaneously, and each sample was assayed twice in duplicate wells.

\section{CEA, SCC and CYFRA21-1 Assay}

Serum CEA and CYFRA21-1 were assessed by an electrochemiluminescence immunoassay using E170 analyzer (Roche Diagnostics Gmbh, Roche, USA). Serum SCC-Ag was measured by a microparticle enzyme immunoassay (ABBOTT Diagnostics, Abbott, USA).

\section{Statistical Analysis}

All statistical analyses were performed using the SPSS 16.0 software package. The cut-off value for seropositivity of CDC25B-Abs was identified by the ROC curve. Pearson's chi-square test or Fisher's exact test was employed to assess the association between CDC25B seropositivity and clinicopathologic characteristics. The statistical difference in CDC25B-Abs levels between patients with tumors and healthy control subjects was evaluated using the Mann-Whitney U test. Survival curves were estimated by Kaplan-Meier plots and log-rank tests. Cox proportional hazard regression analysis was used to estimate the hazard ratios of independent factors for survival. $\mathrm{P}<0.05$ in all case was considered statistically significant.

\section{Results}

Anti-CDC25B autoantibodies in sera of patients with ESCC One hundred thirty-four patients with ESCC were enrolled in the study (Table 1). The presence of CDC25B autoantibodies in sera of ESCC patients was assessed by reverse capture ELISA. The extract of Eca109 cells, which presented the highest CDC25B protein level among the ESCC tumor cell lines tested (Eca-109, Kyse140, TE-1 and the immortalized cell line NE-3) (Figure 1A), was used as the source of CDC25B antigen for reverse capture ELISAs. To determine the optimal amount of Eca-109 cell extract for use in these assays, 20 sera samples from ESCC patients and 20 sera samples from healthy controls were evaluated by reverse capture ELISA. As shown in Figure 1B, $10 \mu \mathrm{g} /$ well of total Eca-109 cell protein was determined to be the optimal protein concentration. The within-run coefficient of variation $(\mathrm{CV})$ for a patient sample (OD 1.35) and a healthy control sample (OD 0.23 ) were $10.3 \%$ and $9.1 \%$, respectively, as determined by repeating the assay 20 times. Under these conditions, the average absorbance was $0.378(\mathrm{SD}=0.262)$ in sera from 134 healthy control subjects and $0.917(\mathrm{SD}=0.473)$ in sera from 134 patients with primary ESCC (Figure 2A). The circulating levels of CDC25B-Abs in patients with ESCC were significantly higher than those of healthy control subjects $(P<0.001)$.

\section{Sensitivity and specificity of serum CDC25B-Abs, CEA, SCC and CYFRA21-1 in detection of ESCC}

The ROC curve was plotted to identify a cut-off value that would distinguish ESCC from nonmalignant esophageal diseases. According to the ROC curve, the optimal cut-off value was 0.725 , providing a sensitivity of $56.7 \%$ and a specificity of $91.0 \%$. The area under the ROC curve for CDC25B-Abs was 0.870 (95\% CI: $0.835-$ 0.920; Figure 2B). CDC25B-Abs were found in sera from 76 of 134 (56.7\%) patients with ESCC, but in sera from only 11 of $134(8.2 \%)$ healthy controls. Serum CDC25BAbs were detected in a higher proportion of patients with ESCC than healthy control subjects $(P<0.001$, 
Table 1 Association between the clinical pathologic features of ESCC and the presence of CDC25B-Abs

\begin{tabular}{|c|c|c|c|c|c|}
\hline \multirow[b]{2}{*}{ Characteristics } & \multirow[b]{2}{*}{ Total $(n=134)$} & \multirow[b]{2}{*}{$\mathrm{OD}(\mathrm{SD})$} & \multicolumn{2}{|c|}{ CDC25B-Abs } & \multirow[b]{2}{*}{$P$} \\
\hline & & & Positive cases n (\%) & Negative cases n (\%) & \\
\hline \multicolumn{6}{|l|}{ Gender } \\
\hline Male & 93 & $0.913(0.496)$ & $48(51.6)$ & $45(48.4)$ & 0.053 \\
\hline Female & 41 & $0.921(0.431)$ & $28(68.3)$ & $13(31.7)$ & \\
\hline \multicolumn{6}{|l|}{ Age (y) } \\
\hline$<60$ & 73 & $0.871(0.491)$ & $44(60.3)$ & $29(47.5)$ & 0.231 \\
\hline$\geq 60$ & 61 & $0.968(0.458)$ & $32(52.5)$ & $29(39.7)$ & \\
\hline \multicolumn{6}{|l|}{ Stage } \\
\hline$|-| \mid$ & 80 & $0.892(0.478)$ & $37(46.3)$ & $43(53.7)$ & 0.002 \\
\hline||$|-| \mathrm{V}$ & 54 & $0.958(0.481)$ & $39(72.2)$ & $15(27.8)$ & \\
\hline \multicolumn{6}{|l|}{ pT classification } \\
\hline $\mathrm{T} 1-\mathrm{T} 2$ & 48 & $0.904(0.482)$ & $28(58.3)$ & $20(41.7)$ & 0.461 \\
\hline T3-T4 & 86 & $0.919(0.477)$ & $48(55.8)$ & $38(44.2)$ & \\
\hline \multicolumn{6}{|l|}{ pN classification } \\
\hline YES & 53 & $0.980(0.511)$ & $29(54.7)$ & $24(45.3)$ & 0.420 \\
\hline NO & 81 & $0.873(0.451)$ & $47(58.0)$ & $34(42.0)$ & \\
\hline \multicolumn{6}{|l|}{ Metastasis } \\
\hline YES & 8 & $0.917(0.436)$ & $3(37.5)$ & $5(62.5)$ & 0.222 \\
\hline NO & 126 & $0.932(0.484)$ & $73(57.9)$ & $53(42.1)$ & \\
\hline
\end{tabular}

OD: optical density

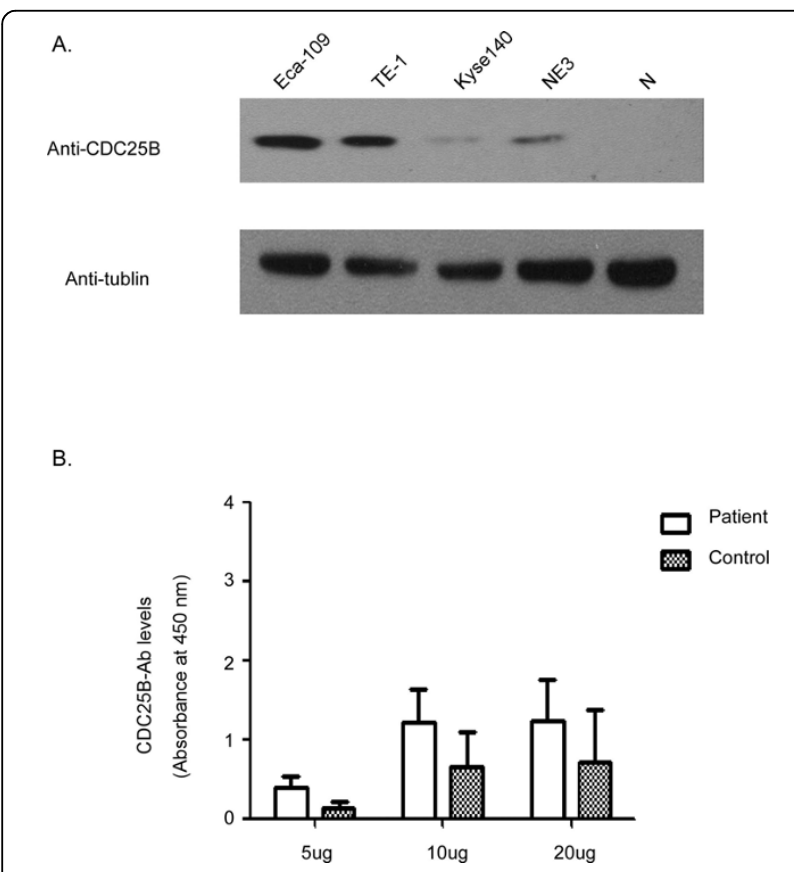

Figure 1 Expression of CDC25B in different ESCC cell lines and optimization of antigen concentration for ELISA assays. A.

Expression of CDC25B in ESCC cell lines was examined by Western blot analysis with an anti-CDC25B antibody (N: normal esophageal tissue). B. Effect of different amounts of Eca-109 total protein on absorbance at $450 \mathrm{~nm}$ in CDC25B-Abs reverse capture ELISA. Twenty samples from patients with ESCC and twenty samples from healthy controls were tested in reverse capture ELISAs using different amounts of Eca-109 total protein as antigen. The results shown are the mean values of three experiments.
Figure 2A); however, sera from only $17.2 \%$ of ESCC patients contained SCC-Ag at levels above the cut-off value of $1.5 \mathrm{ng} / \mathrm{ml}, 13.4 \%$ of ESCC patients contained CEA at levels above the cut-off value of $5.0 \mathrm{ng} / \mathrm{ml}$ and $32.1 \%$ of ESCC patients with the sera CYFRA21-1 levels above the cut-off value of $3.5 \mathrm{ng} / \mathrm{ml}$. (Table 2). These data indicate that the percentage of CDC25B-Abs seropositivity in patients with ESCC is dramatically higher the percentages of seropositivity of the previously described tumor markers SCC-Ag, CEA and CYFRA211 in these patients. In addition, sera from $41.0 \%$ of patients with ESCC were positive for CEA, SCC-Ag or CYFRA21-1, while sera from $64.2 \%$ of patients with ESCC were positive for CEA, SCC-Ag, CYFRA21-1 or CDC25B-Abs (Table 2). The sensitivity of these four markers used in combination was slightly higher than that of the CDC25B-Abs marker alone but significantly higher than that of CEA, SCC-Ag and CYFRA21-1 used in combination $(P<0.001)$.

\section{Association between CDC25B-Abs and Clinicopathological Characteristics}

The data presented in Table 1 show the relationship between CDC25B-Abs and clinicopathological variables in ESCC. CDC25B-Abs were not obviously correlated with $\mathrm{T}$ classification, $\mathrm{N}$ classification or metastasis; however, there was a significant association between the presence of CDC25B-Abs and ESCC clinical stage $(P=$ 0.002). The percentage of CDC25B-Abs seropositivity was higher in patients with advanced disease than in patients with early disease. 


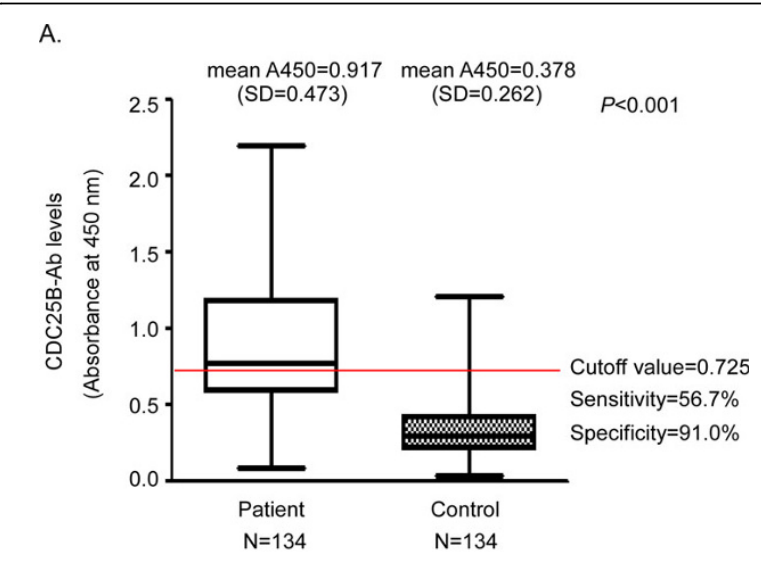

B.

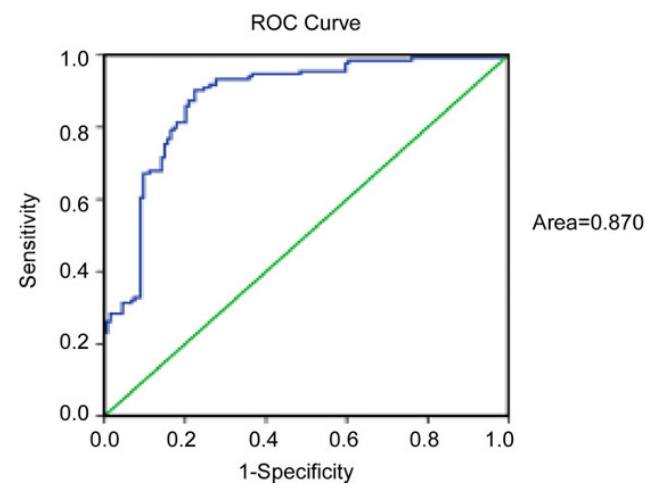

Figure 2 CDC25B autoantibodies in sera from patients with ESCC and healthy controls and ROC Curve analysis. A. CDC25BAbs were detected by reverse capture ELISA in sera from patients with ESCC (Patient) and healthy controls (Control). The horizontal line indicates the cut-off value used to define positive samples. The results shown are the mean values of two independent experiments. B. ROC curve of CDC25B-Abs in sera from patients with ESCC. The area under the ROC curve is 0.870 . The cut-off value is determined according to the ROC curve.

Table 2 The sensitivity of CDC25B-Abs, CEA, CYFRA21-1 and SCC-Ag in detection ESCC

\begin{tabular}{lllll}
\hline Tumor Markers & $\begin{array}{l}\text { Total } \\
\mathbf{n}\end{array}$ & Positive & Negative \\
\cline { 3 - 4 } & & $\mathbf{n}(\%)$ & $\mathbf{n}(\%)$ & $\boldsymbol{P}$ \\
\hline CDC25B-Abs & 134 & $76(56.7)$ & $58(43.3)$ & \\
SCC-Ag & 134 & $23(17.2)$ & $111(82.8)$ & \\
CEA & 134 & $18(13.4)$ & $116(86.6)$ & \\
CYFRA 21-1 & 134 & $43(32.1)$ & $91(67.9)$ & \\
CEA, SCC-Ag & 134 & $55(41.0)$ & $79(59.0)$ & \\
Or CYFRA21-1 & & & & \\
CEA, SCC-Ag, & 134 & $86(64.2)$ & $48(35.8)$ & $<0.001^{*}$ \\
\multicolumn{2}{l}{ CYFRA21-1 or CDC25B-Abs } & & & \\
\hline
\end{tabular}

Abs: antibodies; CEA: carcinoembryonic antigen; SCC-Ag: squamous cell carcinoma antigen; CYFRA21-1: cytokeratin 19 fragment antigen 21-1.

*compared with either CEA, SCC-Ag or CYFRA21-1. Cut-off values: $5.0 \mathrm{ng} / \mathrm{ml}$ for CEA; $1.5 \mathrm{ng} / \mathrm{ml}$ for SCC-Ag; $3.5 \mathrm{ng} / \mathrm{ml}$ for CYFRA21-1

\section{Association of CDC25B-Abs with Survival}

The overall survival of ESCC patients was plotted using the Kaplan-Meier method, and a log-rank test was employed to evaluate the prognostic significance of CDC25B-Abs. There was no statistical difference between the survival rate of the $\mathrm{CDC} 25 \mathrm{~B}$-seronegative patients and that of the $\mathrm{CDC} 25 \mathrm{~B}$-seropositive patients $(P=0.992)$ (Figure 3A). We then analyzed the potential prognostic value of $\mathrm{CDC} 25 \mathrm{~B}$-Abs in different subgroups of patients stratified according to the clinical stage of the patient's tumor, $\mathrm{T}$ classification and $\mathrm{N}$ classification. As shown in Figure 3, for the subgroup with clinical stage III-IV tumors, the cumulative five-year survival rate was $43.4 \%$ in the $\mathrm{CDC} 25 \mathrm{~B}$-seronegative patients and $6.7 \%$ in the CDC25B-seropositive patients $(P=$ $0.001, \log$-rank). In a similar analysis of the N1 subgroup, the cumulative five-year survival rate was $54.5 \%$

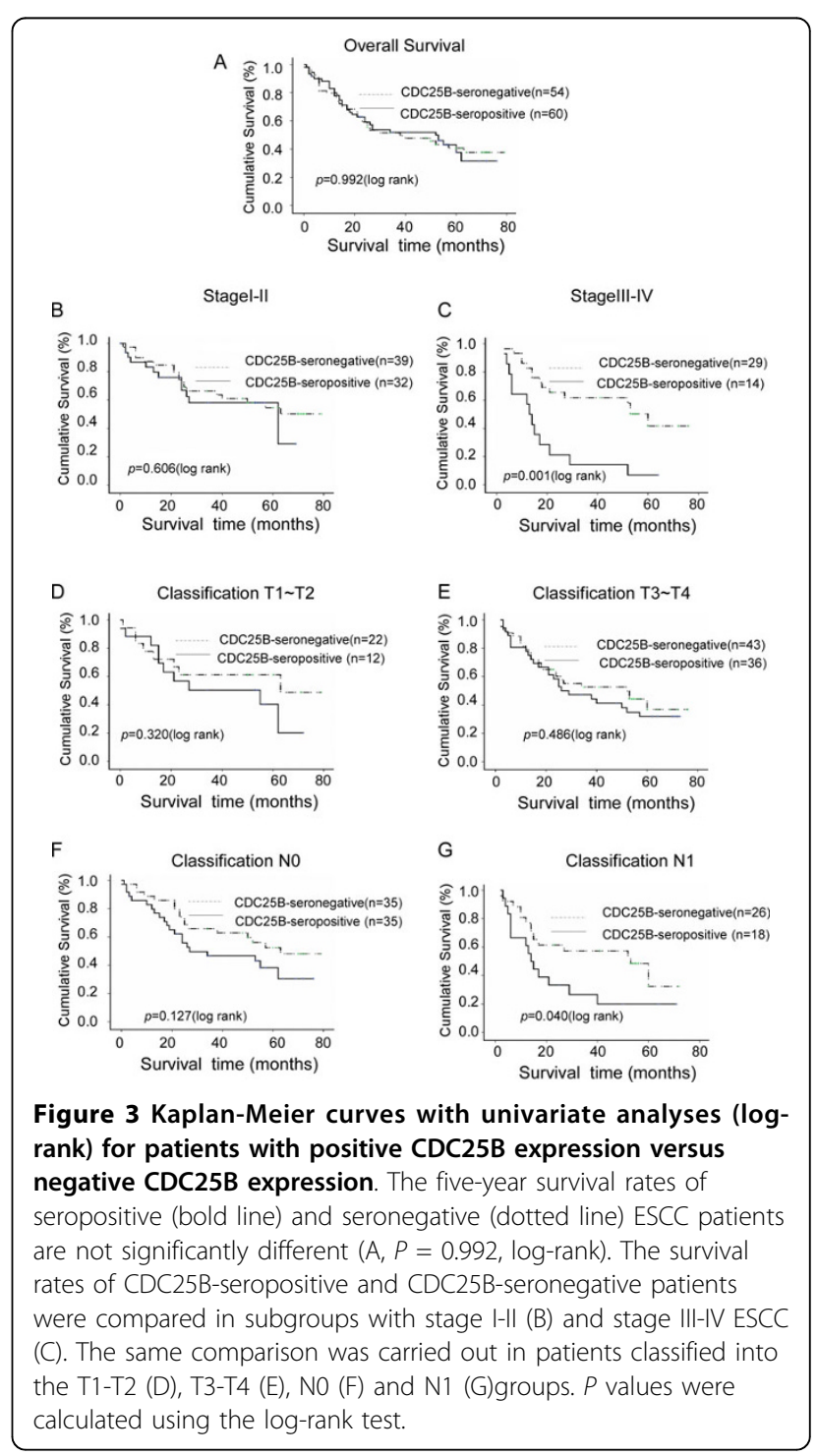


Table 3 Univariate and multivariate analysis of different prognostic parameters in ESCC patients in the N1 subgroup by Cox regression analysis

\begin{tabular}{|c|c|c|c|c|c|c|}
\hline & \multicolumn{2}{|c|}{ Univariate analysis } & \multicolumn{4}{|c|}{ Multivariate analysis } \\
\hline & No. patients & $P$ & Regression coefficient(SE) & $P$ & Relative risk & 95\% confidence interval \\
\hline \multicolumn{7}{|l|}{ pT classification } \\
\hline $\mathrm{T} 1-\mathrm{T} 2$ & 7 & 0.015 & $0.405(0.196)$ & 0.040 & 1.499 & $1.020-2.202$ \\
\hline T3-T4 & 37 & & & & & \\
\hline \multicolumn{7}{|l|}{ CDC25B-Abs } \\
\hline Seronegative & 18 & 0.001 & $0.633(0.196)$ & 0.001 & 1.882 & $1.283-2.762$ \\
\hline Seropositive & 26 & & & & & \\
\hline
\end{tabular}

in the CDC25B-seronegative patients and $13.6 \%$ in the CDC25B-seropositive patients (Figure 3G) $(P=0.040$, log-rank). In addition, multivariate survival analysis was used to determine whether circulating CDC25B-Abs were an independent prognostic factor. Our results showed that the level of circulating CDC25B-Abs had a significant relationship with the prognosis of patients with advanced ESCC $(P=0.001)$ (Table 3$)$; however, the difference between CDC25B-seropositive patients and CDC25B-seronegative patients was not statistically significant in patients classified into the stage I-II $(P=$ 0.606, log-rank; Figure 3B), T1-T2 $(P=0.320$, log-rank; Figure 3D), T3-T4 $(P=0.486$, log-rank; Figure $3 \mathrm{E})$ and N0 $(P=0.127$, log-rank; Figure $3 F)$ subgroups.

\section{Discussion}

The identification of tumor antigens that elicit an immune response is important for clinical applications; tumor antigens may used for early diagnosis, prognosis, and immunotherapy against the disease[29]. In this study, we show that CDC25B-Abs in sera from ESCC patients were more sensitive than CEA, SCC-Ag and CYFRA21-1 for diagnosis of ESCC. Moreover, serum levels of CDC25B-Abs were correlated with the clinicopathologic characteristics present in patients with advanced ESCC.

CEA, SCC-Ag and CYFRA21-1 have been used as tumor markers for diagnosis of ESCC [30]. However, reliance on the three tumor markers for the detection of ESCC has not been satisfactory, especially because of the poor sensitivity of these tumor markers for ESCC [31]. In line with previous studies, our current study showed that the sensitivity of CEA, SCC-Ag or CYFRA21-1 for detection of ESCC was less than 35\% [32-34]. To circumvent the problem of low sensitivity, we and others have begun to evaluate the use of autoantibodies against tumor antigens to detect ESCC. Ralhan has shown that anti-p53 antibodies were found in $60 \%$ sera from patients with ESCC[5], and Shimada has reported that anti-p53 antibodies were found in $40 \%$ sera from patients with ESCC and surveillance of serum p53-Abs was superior to CEA, SCC-Ag and CYFRA21-1
[6]. Autoantibody against Prx VI was found in sera from $50 \%$ of patients with ESCC[11]. Serum anti-myomegalin antibodies were present in $47 \%$ of patients with ESCC [8]. Our previous study showed that $36.3 \%$ of ESCC patients with autoantibody responses to CDC25B [12]. These results suggest that autoantibodies increase the sensitivity of detection of ESCC and might be useful tumor markers for ESCC diagnosis.

In the current study, CDC25B autoantibodies were detected in sera of ESCC patients by reverse capture ELISA. This technology is based on capturing specific antigens from tumor cell lysates with antibodies, allowing the antigens to be immobilized in their native configuration [35-37]. Due to optimization of the reverse capture ELISA in current study, the sensitivity of this assay is higher than in our previous report (36.3\%), but its specificity is lower than that reported in our previous study (100\%) [12]. The rate of CDC25B-Abs seropositivity in patients with ESCC was significantly higher than the seropositivity rates of tumor markers SCC-Ag, CEA and CYFRA21-1. Moreover, the combination of CDC25B-Abs and conventional tumor markers, CEA, SCC-Ag, and CYFRA21-1 significantly increased the sensitivity of detection of ESCC. Our data suggest that CDC25B-Abs could be a potential biomarker for ESCC diagnosis.

In addition, our results demonstrate that $\mathrm{CDC} 25 \mathrm{~B}$ autoantibodies were more prevalent in sera from patients with advanced ESCC than in sera from patients with early stage disease $(P<0.001)$ and that in the patients with clinical stage III-IV and N1 subgroup, CDC25B-Abs seronegative patients survived longer than CDC25B-Abs seropositive patients. This observation may be explained by the higher incidence of CDC25B overexpression in advanced ESCC than in early stage tumors[22,25]. CDC25B protein expression increased as tumors progressed; none of the healthy control subjects expressed CDC25B, while one-fourth of the dysplasia subjects and one-half of the patients with invasive cancer expressed CDC25B[25]. Moreover, overexpression of CDC25B was also more frequently found in patients with deep tumor invasion and lymph node metastasis 
than in patients with early stage disease $[22,38]$. Overexpression of CDC25B in advanced ESCC may thus lead to high production of $\mathrm{CDC} 25 \mathrm{~B}$-Abs in patients with advanced tumors. These results suggest that detection of serum CDC25B-Abs is a useful non-invasive marker for identifying advanced ESCC patients with poor prognosis.

In summary, the levels of CDC25B-Abs in sera from ESCC patients were significantly higher than those in sera from healthy subjects. Detection of CDC25B-Abs in combination with CEA, SCC-Ag, CYFRA21-1 results in significantly increased sensitivity of detection, with $64.2 \%$ of ESCC patients testing positive for at least one of these markers. Moreover, our study has demonstrated the prognostic significance of serum CDC25B-Abs in ESCC and the clinical implications of CDC25B-Abs seropositivity on lymph node metastasis and advanced stage ESCC. High levels of CDC25B autoantibodies in sera were significantly associated with poor survival in advanced ESCC. CDC25B autoantibodies are thus a useful prognostic predictor for advanced ESCC.

\section{Conclusions}

Our findings indicate that the levels of CDC25B-Abs in sera from patients with ESCC are significantly higher than those of other tumor markers. Moreover, high levels of CDC25B-Abs were associated with poor survival in advanced ESCC. Multivariate survival analysis showed that CDC25B-Abs are a potential prognostic serological marker for advanced ESCC. CDC25B-Abs therefore provide a valuable serological marker in the prognostic evaluation of advanced ESCC.

\section{Abbreviations \\ ESCC: esophageal squamous cell carcinoma; ELISA: enzyme-linked immunosorbent assay; CEA: carcinoembryonic antigen; SCC-Ag: squamous cell carcinoma antigen; ROC: receiver operating characteristic; PBS: phosphate-buffered; OD: optical density; CDK: cyclin-dependent kinase; CYFRA21-1: cytokeratin 19 fragment antigen 21-1}

\section{Acknowledgements}

This study was supported by grants from the National Natural Science Foundation of China (30630068, 30872931, and 30972762) and the Ministry of Science and Technology of China (No. 2007AA02Z477, 2006DAI02A11, and 2006AA02Z4B4).

\section{Author details}

${ }^{1}$ The Second Affiliated Hospital of Guangzhou Medical University, Gyangzhou, China. ${ }^{2}$ Department of Experimental Research, Sun Yat-sen University Cancer Center, Guangzhou, China. ${ }^{3}$ State Key Laboratory of Oncology in South China and Department of Thoracic, Sun Yat-sen University Cancer Center, Guangzhou, China. ${ }^{4}$ Department of Thoracic, Sun Yat-sen University Cancer Center, Guangzhou, China. ${ }^{5}$ Department of Clinical Laboratory Medicine, Sun Yat-sen University Cancer Center, Guangzhou, China.

\section{Authors' contributions}

MSZ is responsible for the study design. JD and BHZ performed the experiments and drafted the manuscript. LHX participated in the data analysis and Western blots. All authors read and approved the final manuscript.

\section{Competing interests}

The authors declare that they have no competing interests.

Received: 8 March 2010 Accepted: 3 September 2010

Published: 3 September 2010

\section{References}

1. Enzinger PC, Mayer RJ: Esophageal cancer. N Engl J Med 2003, 349:2241-2252.

2. Lerut T, Coosemans W, De Leyn P, Van Raemdonck D, Deneffe G, Decker G: Treatment of esophageal carcinoma. Chest 1999, 116:463S-465S.

3. Shimada H, Nabeya $Y$, Okazumi S, Matsubara H, Shiratori T, Gunji $Y$, Kobayashi S, Hayashi H, Ochiai T: Prediction of survival with squamous cell carcinoma antigen in patients with resectable esophageal squamous cell carcinoma. Surgery 2003, 133:486-494.

4. Sobin LH, Fleming ID: TNM Classification of Malignant Tumors, fifth edition (1997). Union Internationale Contre le Cancer and the American Joint Committee on Cancer. Cancer 1997, 80:1803-1804.

5. Ralhan R, Arora S, Chattopadhyay TK, Shukla NK, Mathur M: Circulating p53 antibodies, p53 gene mutational profile and product accumulation in esophageal squamous-cell carcinoma in India. Int J Cancer 2000, 85:791-795.

6. Shimada H, Nabeya Y, Okazumi S, Matsubara H, Funami Y, Shiratori T, Hayashi H, Takeda A, Ochiai T: Prognostic significance of serum p53 antibody in patients with esophageal squamous cell carcinoma. Surgery 2002, 132:41-47.

7. Takahashi K, Miyashita M, Nomura T, Makino H, Futami R, Kashiwabara M, Katsuta M, Tajiri T: Serum p53 antibody as a predictor of early recurrence in patients with postoperative esophageal squamous cell carcinoma. Dis Esophagus 2007, 20:117-122.

8. Shimada H, Kuboshima M, Shiratori T, Nabeya Y, Takeuchi A, Takagi H, Nomura F, Takiguchi M, Ochiai T, Hiwasa T: Serum anti-myomegalin antibodies in patients with esophageal squamous cell carcinoma. Int J Oncol 2007, 30:97-103.

9. Kuboshima M, Shimada H, Liu TL, Nomura F, Takiguchi M, Hiwasa T, Ochiai T: Presence of serum tripartite motif-containing 21 antibodies in patients with esophageal squamous cell carcinoma. Cancer Sci 2006, 97:380-6.

10. Fujita $Y$, Nakanishi T, Miyamoto $Y$, Hiramatsu M, Mabuchi H, Miyamoto A, Shimizu A, Takubo T, Tanigawa N: Proteomics-based identification of autoantibody against heat shock protein 70 as a diagnostic marker in esophageal squamous cell carcinoma. Cancer Lett 2008, 263:280-290,

11. Shimada H, Nakashima K, Ochiai T, Nabeya Y, Takiguchi M, Nomura F, Hiwasa T: Serological identification of tumor antigens of esophageal squamous cell carcinoma. Int $J$ Oncol 2005, 26:77-86.

12. Liu WL, Zhang G, Wang JY, Cao JY, Guo XZ, Xu LH, Li MZ, Song LB, Huang WL, Zeng MS: Proteomics-based identification of autoantibody against $C D C 25 B$ as a novel serum marker in esophageal squamous cell carcinoma. Biochem Biophys Res Commun 2008, 375:440-445.

13. Nilsson I, Hoffmann I: Cell cycle regulation by the Cdc25 phosphatase family. Prog Cell Cycle Res 2000, 4:107-114.

14. Galaktionov K, Lee AK, Eckstein J, Draetta G, Meckler J, Loda M, Beach D: CDC25 phosphatases as potential human oncogenes. Science 1995, 269:1575-1577.

15. Cangi MG, Cukor B, Soung P, Signoretti S, Moreira G Jr, Ranashinge M, Cady B, Pagano M, Loda M: Role of the Cdc25A phosphatase in human breast cancer. J Clin Invest 2000, 106:753-761.

16. Mailand N, Podtelejnikov AV, Groth A, Mann M, Bartek J, Lukas J: Regulation of $\mathrm{G}(2) / \mathrm{M}$ events by $\mathrm{Cdc} 25 \mathrm{~A}$ through phosphorylation-dependent modulation of its stability. Embo J 2002, 21:5911-5920.

17. Takemasa I, Yamamoto H, Sekimoto M, Ohue M, Noura S, Miyake Y, Matsumoto T, Aihara T, Tomita N, Tamaki Y, et al: Overexpression of CDC25B phosphatase as a novel marker of poor prognosis of human colorectal carcinoma. Cancer Res 2000, 60:3043-3050.

18. Ito Y, Yoshida H, Tomoda C, Uruno T, Takamura Y, Miya A, Kobayashi K, Matsuzuka F, Kuma K, Nakamura Y, et al: Expression of cdc25B and cdc25A in medullary thyroid carcinoma: cdc25B expression level predicts a poor prognosis. Cancer Lett 2005, 229:291-297.

19. Kristjansdottir K, Rudolph J: Cdc25 phosphatases and cancer. Chem Biol 2004, 11:1043-1051. 
20. Hernandez S, Hernandez L, Bea S, Cazorla M, Fernandez PL, Nadal A, Muntane J, Mallofre C, Montserrat E, Cardesa A, Campo E: cdc25 cell cycleactivating phosphatases and c-myc expression in human non-Hodgkin's lymphomas. Cancer Res 1998, 58:1762-1767.

21. Sasaki H, Yukiue H, Kobayashi Y, Tanahashi M, Moriyama S, Nakashima Y, Fukai I, Kiriyama M, Yamakawa Y, Fujii Y: Expression of the cdc25B gene as a prognosis marker in non-small cell lung cancer. Cancer Lett 2001, 173:187-192.

22. Nishioka K, Doki Y, Shiozaki H, Yamamoto H, Tamura S, Yasuda T, Fujiwara Y, Yano M, Miyata H, Kishi K, Nakagawa H, Shamma A, Monden M: Clinical significance of CDC25A and CDC25B expression in squamous cell carcinomas of the oesophagus. Br J Cancer 2001, 85:412-21.

23. Hu YC, Lam KY, Law S, Wong J, Srivastava G: Identification of differentially expressed genes in esophageal squamous cell carcinoma (ESCC) by CDNA expression array: overexpression of Fra-1, Neogenin, Id-1, and CDC25B genes in ESCC. Clin Cancer Res 2001, 7:2213-2221.

24. Xue LY, Hu N, Song YM, Zou SM, Shou JZ, Qian LX, Ren LQ, Lin DM, Tong T, He ZG, Zhan QM, Taylor PR, Lu N: Tissue microarray analysis reveals a tight correlation between protein expression pattern and progression of esophageal squamous cell carcinoma. BMC Cancer 2006, 6:296

25. Shou JZ, Hu N, Takikita M, Roth MJ, Johnson LL, Giffen C, Wang QH, Wang C, Wang Y, Su H, et al: Overexpression of CDC25B and LAMC2 mRNA and protein in esophageal squamous cell carcinomas and premalignant lesions in subjects from a high-risk population in China. Cancer Epidemiol Biomarkers Prev 2008, 17:1424-1435.

26. Zhang H, Jin Y, Chen X, Jin C, Law S, Tsao SW, Kwong YL: Cytogenetic aberrations in immortalization of esophageal epithelial cells. Cancer genetics and cytogenetics 2006, 165:25-35.

27. Song LB, Zeng MS, Liao WT, Zhang L, Mo HY, Liu WL, Shao JY, Wu QL, $\mathrm{Li} M \mathrm{M}$, Xia YF, et al: Bmi-1 is a novel molecular marker of nasopharyngeal carcinoma progression and immortalizes primary human nasopharyngeal epithelial cells. Cancer Res 2006, 66:6225-6232.

28. Guo XZ, Zhang G, Wang JY, Liu WL, Wang F, Dong JQ, Xu LH, Cao JY, Song LB, Zeng MS: Prognostic relevance of Centromere protein $\mathrm{H}$ expression in esophageal carcinoma. BMC Cancer 2008, 8:233.

29. Finn OJ: Immune response as a biomarker for cancer detection and a lot more. N Engl J Med 2005, 353:1288-1290.

30. Mealy K, Feely J, Reid I, McSweeney J, Walsh T, Hennessy TP: Tumour marker detection in oesophageal carcinoma. Eur I Surg Oncol 1996, 22:505-507.

31. Munck-Wikland E, Kuylenstierna R, Wahren B, Lindholm J, Haglund S: Tumor markers carcinoembryonic antigen, CA 50, and CA 19-9 and squamous cell carcinoma of the esophagus. Pretreatment screening. Cancer 1988, 62:2281-2286

32. Yi Y, Li B, Wang Z, Sun H, Gong H, Zhang Z: CYFRA21-1 and CEA are useful markers for predicting the sensitivity to chemoradiotherapy of esophageal squamous cell carcinoma. Biomarkers 2009, 14:480-485.

33. Yamamoto K, Oka M, Hayashi H, Tangoku A, Gondo T, Suzuki T: CYFRA 21-1 is a useful marker for esophageal squamous cell carcinoma. Cancer 1997, 79:1647-1655.

34. Chen W, Abnet CC, Wei WQ, Roth MJ, Lu N, Taylor PR, Pan QJ, Luo XM, Dawsey SM, Qiao YL: Serum markers as predictors of esophageal squamous dysplasia and early cancer. Anticancer Res 2004, 24:3245-3249.

35. Ehrlich JR, Qin S, Liu BC: The 'reverse capture' autoantibody microarray: a native antigen-based platform for autoantibody profiling. Nat Protoc 2006, 1:452-460

36. Ehrlich JR, Tang L, Caiazzo RJ Jr, Cramer DW, Ng SK, Ng SW, Liu BC: The "reverse capture" autoantibody microarray: an innovative approach to profiling the autoantibody response to tissue-derived native antigens. Methods Mol Biol 2008, 441:175-192.

37. Qin S, Qiu W, Ehrlich JR, Ferdinand AS, Richie JP, O'Leary MP, Lee ML, Liu BC: Development of a "reverse capture" autoantibody microarray for studies of antigen-autoantibody profiling. Proteomics 2006, 6:3199-3209.

38. Miyata $H$, Doki $Y$, Shiozaki $H$, Inoue $M$, Yano $M$, Fujiwara $Y$, Yamamoto $H$, Nishioka K, Kishi K, Monden M: CDC25B and p53 are independently implicated in radiation sensitivity for human esophageal cancers. Clin Cancer Res 2000, 6:4859-4865. doi:10.1186/1479-5876-8-81

Cite this article as: Dong et al: Anti-CDC25B autoantibody predicts poor prognosis in patients with advanced esophageal squamous cell carcinoma. Journal of Translational Medicine 2010 8:81.

\section{Submit your next manuscript to BioMed Central and take full advantage of:}

- Convenient online submission

- Thorough peer review

- No space constraints or color figure charges

- Immediate publication on acceptance

- Inclusion in PubMed, CAS, Scopus and Google Scholar

- Research which is freely available for redistribution

Submit your manuscript at www.biomedcentral.com/submit 